University of Nebraska - Lincoln

DigitalCommons@University of Nebraska - Lincoln

P. F. (Paul Frazer) Williams Publications

Electrical \& Computer Engineering, Department

July 1988

\title{
Physical mechanism of triggering in trigatron spark gaps
}

\author{
F. E. Peterkin \\ University of Nebraska - Lincoln \\ P. F. Williams \\ University of Nebraska - Lincoln, pfw@moi.unl.edu
}

Follow this and additional works at: https://digitalcommons.unl.edu/elecengwilliams

Part of the Electrical and Computer Engineering Commons

Peterkin, F. E. and Williams, P. F., "Physical mechanism of triggering in trigatron spark gaps" (1988). P. F. (Paul Frazer) Williams Publications. 5.

https://digitalcommons.unl.edu/elecengwilliams/5

This Article is brought to you for free and open access by the Electrical \& Computer Engineering, Department of at DigitalCommons@University of Nebraska - Lincoln. It has been accepted for inclusion in P. F. (Paul Frazer) Williams Publications by an authorized administrator of DigitalCommons@University of Nebraska - Lincoln. 


\title{
Physical machanism of triggering in trigatron spark gaps
}

\author{
F. E. Peterkin and P.F. Williams \\ Department of Electrical Engineering, University of Nebraska-Lincoln, Lincoin. Nebraska 68588-0511
}

(Received 9 March 1988; accepted for publication 17 May 1988)

\begin{abstract}
Since the first trigatron spark gap was describsd by J. D. Craggs, M. E. Haine, and J. M. Meek [J. Inst. Electr. Eng. 93A, 963 (1946)], there has been controversy about the physical mechanisn responsible for triggering the devices. In this letter we present experimental evidence that directly shows the sequence of physica? events responsible for triggering in the gap we studied, and we present a model for trigatron triggering based on this information. We believe this model to be general and discuss it in light of existing literature. We briefly discuss the implications of the rodel for the engineering design of trigatron gaps.
\end{abstract}

The trigatron spark gap was invented in the early 1940 's to serve as a switch in high-power modulators for radar, ${ }^{1,2}$ and has found wide application as a high voltage, high current switch. A trigatron spark gap has three electrodes, two of which form the main gap. The third, the trigger pin, is located inside a hole in one of the main gap electrodes. In operation, a voltage less than the static main gap breakdown voltage, $F_{S B}$, is applied to the main gap and breakdown is triggered by the application of a voltage pulse to the trigger pin. There is disagreement about the physical mechanism responsible for triggering breakdown of the main gap. The most common view in the technical hiterature is that the breakdown of the main gap is initiated after the gap between the trigger pin and the adjacent main gap electrode breaks down, and is the result of the action of this spark. ${ }^{1-9}$ Another viewpoint is that breakdown occurs as a result of the formation of a streamer in the distorted field around the trigger pin tip before the formation of the trigger spark. ${ }^{10-15}$

This long-standing controversy is due in part to the fact that both viewpoints are based mostly on indirect experimental evidence such as current and voltage traces which must be interpreted in terms of a specific model. In this letter we present recent experimental results which clearly and directly support the second viewpoint, and clarify the detailed succession of events cccurring during the initial stages of triggered breakdown. We believe our conclusions to be genteral and to impact directly several design questions for trigatron spark gap switches as well as other types of triggered spark gap switches.

Figure 1 shows a schematic drawing of our experimental apparatus. A trigatron spark gap was placed inside a metal housing which could be evacuated and then back flled. Gap spacing was adjustable, but for most experiments was set at $2.5 \mathrm{~cm}$, resulting in $V_{\mathrm{SB}}=62 \mathrm{kV}$ for a 700 Tor $\mathrm{N}_{2}$ flll. The gap was designed to appear as a $50 \Omega$ constant impedance transmission line. Voltage was supplied to the gap by a d.c.charged, $50 \Omega, 20$ ns coaxial cable, and the gap discharged into a matched load. The trigger generator consisted of an $800 \mathrm{~ns}, 50 \Omega$, d.c.-charged coaxial cable switched by a lasertriggered spark gap. The rise time of the trigger pulse at the trigger pin tip was $10-20$ ns. Capacitive voltage probes with $\approx 2$ ns rise time monitored trigger pin and main gap woltages. A low inductance current viewing resistor in the load provided a monitor of load current. Optical events in the gap were recorded with a high sensitivity streak camera and a locally constructed two-dimensional shutter camera capable of about $5 \mathrm{~ns}$ temporal resolution.

Figure 2 shows a typical two-dimensional shutter photograph of streamers in the trigatron gap obtained under conditions listed in the caption. Figure 3 shows a typical streak photograph obtained under the same conditions, along with the gap current for the same shot. The photos show very clearly a luminous front crossing the gap. This front was the first optical event observed in the main gap, and is certainly a record of the passage of a streamer. Several streamers are launched from the trigger pin, each with a diameter of about $2 \mathrm{~mm}$, and propagate with a speed varying between about $10^{8}$ and more than $10^{9} \mathrm{~cm} / \mathrm{s}$. In almost all cases, however, the are forms from only one of these streamer channels. The intensity of the emission from these fronts is very weak. Much more intense emission is observed later as the streamer channel heats and the are starts to form.

Except for the arrival of the trigger pulse, current associated with this front is the first electrical event observable in the main gap. Starting within a few us of the time the streamer appears at the trigger pin tip on the streak photo, the gap current starts to rise. This current is the result of the motion of free electrons in the streamer tip, ahead of the streamer (produced by photoionization or photoemission), and inside the streamer body. The plasma of the streamer tends to shicld the streamer interior from the external field, but is only partially successful because of the rapidly changing conditions produced by the propagating streamer tip. The gap current rises primarily because the number of free electrons inside the streamer body increases as the sireamer channei lengthens. As the streamer nears the distant electrode, shielding of the interior becones increasingly dificult because the external circuit maintains a constant potential

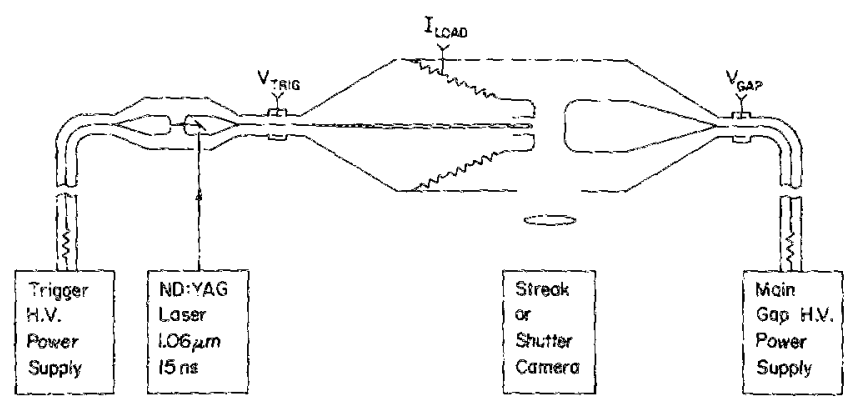

FIC. 1. Schematic diagram of the experimental setup. 


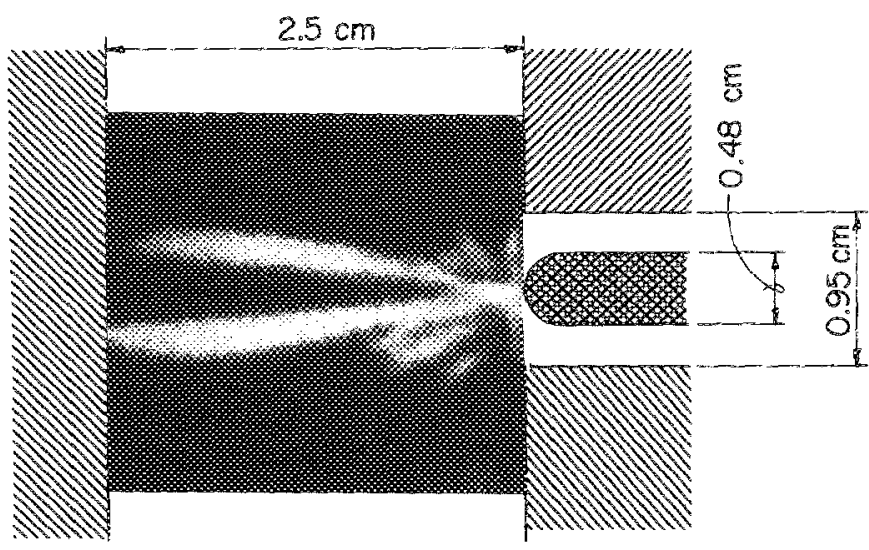

FIG. 2. Two-dimensional shutter photograph showing streanters in the gap. The conditions were $-60 \mathrm{kV}$ charging yoltage $+10 \mathrm{kV}$ trigger voltage, and 700 Torm $\mathbb{N}_{2}$ fill. The shutter was open for $\approx 5 \mathrm{~ns}$, and closed at a time roughly corresponding to 10 ns on the current trace in Fig. 3. Arc formation and gap closure occurred $20-30$ ns later.

drop between the trigger and main gap electrodes. Some of the current increase may, therefore, also be due to a decrease in shielding efficiency.

In most cases, the gap current jumped simultaneously ( \pm 1 ns) with the streamer arriving at the opposite main gap electrode. When the streamer contacts this electrode, the requirement of constant potential drop is inconsistent with significant shielding of the main streamer body, and the field inside the streamer must rise. ${ }^{17}$ This effect is seen in the electrical diagnostic as this current jump, and in the optical

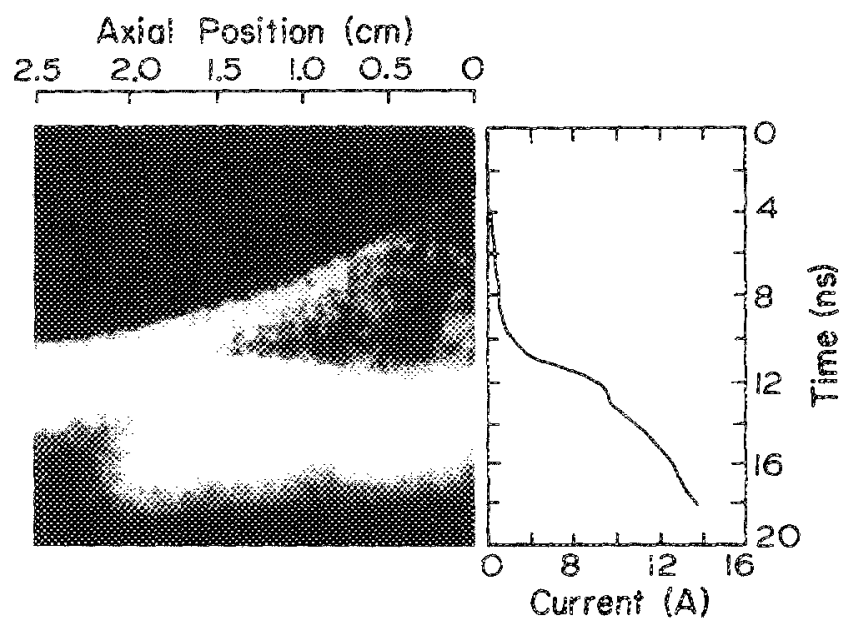

FIG. 3. Streak photograph and corresponding current trace associated with a streamer propagating across the gap. Conditions were the same is in Fig. 2. The streak camera viewed a 1.2 -rnm-wide slit containing the gap axis. The current trace was obtained by measuring the voltage at $F_{G A P}$ in Fig. 1 , and is nearly independent of the trigger gap current before main gap breskdown. The synchronization of the time scales of the streak photo and the current trace is accurate to within $\mathrm{ns}$. diagnostic as a sudden increase in luminosity. Neglecting any voltage drop across the electrode-plasma interfaces, we estimate the resistance of the streamer channel at this time to be somewhat larger than $6 \mathrm{k} \Omega$, and the average free-electron density in the streamer channe to lie in the range $10^{14}-10^{15}$ $\mathrm{cm}^{-3}$, in good agreement with theoretical expectation. ${ }^{18}$

The experimental results we have obtained show that triggered breakdown of our trigatron spark gap occurs through the following secuence of events. Upon arrival of the trigger pulse at the trigger pin streamers form after a short delay and propagate across the gan. One or more streamer channeis then connect the trigger pin to the opposite main gap electrode through a high resistance $(\approx 10 \mathrm{k} \Omega)$, and the switch is still open. The applied field causes the ionization density in these streamer channels to rise, decreasing this resistance. Concurrently, as seen in two-dimensional shutter photographs not shown here, the gap between the trigger pin and the adjacent main gap electrode also undergoes a streamer/channel-heating breakdown process. The detailed sequence of events beyond this point is complex, depending on the relative timing of these two breakdown processes, the source resistance and pulse length of the trigger generator, and the main gap charging voltage. In most cases the final result is two thermalized arcs connecting the trigger pin to the opposite main gap electrode and the adjan cent electrode, but other final configurations are probably possible, and control of this stage provides the engineer with an opportunity to optimize gap performance.

Physically, the breakdown is a two-step process. First, one or more streamers form and propagate across the main gap. Second, the resulting ionization density, driven by the appiled field, increases until the arc channel forms and the switch is closed. The enhanced ficle at the trigger pin tip is needed only to launch the streamer. Once the streamer has bridged some fraction of the gap, the presence of voltage on the pin may aid the breakdown process, but it is not needed for breakdown to occur.

These conclusions have important inplications for the design of trigatrons, and the question of the generality of our observations naturally arises. We have performed similar experiments for $\mathrm{N}_{2}$ fills between 250 and 900 Torr; synthetic air and $\mathrm{H}_{2}$ fills at 700 Torr; trigger pin diameters between 0.08 and $0.5 \mathrm{~cm}$; rounded, squared-ofi, and ring-shaped pin tips; pins ffush with and recessed below the host electrode surface, charging voltages between $\approx 25$ and $99 \%$ of static self-break voltage ( $15-62 \mathrm{kV}$ for 700 Torr $\mathrm{N}_{2}$ ); trigger pulse voltages between 5 and $25 \mathrm{kV}$; and both heteropolar charging configurations ( + trigger, - main gap, and vice versa). Except for very low charging voltages or very short trigger gaps, breakdown of the main gap was always initiated by a streamer launched from the trigger pin before breakdown of the rrigger gap.

Shkuropat studied the dependence of gap current and voltage traces on the polarity configuration ard trigger gap conditions in trigatrons, and concluded that breakdown is initiated by feld distortion at the trigger pin tip. "He later presented photographic evidence showing several generations of luminous filaments in the gap before the breakdown of the main gap, and concluded that breakdown occurs in 
two stages. ${ }^{13}$ Martin has described a pheromenological model for breakdown in high voltage gaps which he has applied to trigatrons, and concluded that breakdown consists of a sequence of events similar to those we report." Very recent experimental results by Wells ${ }^{16}$ also support our model.

Most other workers have attributed triggering to effects of the trigger spark that forms between the trigger pin and the adjacent main gap electrode. ${ }^{1-9}$ The principal argument they use is based on excluding field distortion mechanisns, and implicitly assumes that breakdown is a single-step process. Since the main gap is often found to break down after the trigger gap, field distortion mechanisms are excluded by reasoning that when the trigger gap breaks down the rrigger woltage collapses, removing the field distortion, and terminating the main gap breakdown process if it has not already been completed. The breakdown mechanism we suggest is a two-step process, and such arguments cannot be used to exclude it. We therefore believe the model to be consistent with most pubished experimental results on trigatrons.

The results we present here have several implications for the design of trigatrons. For example, high ficlds near the trigger pin tip are probably needed to reduce delay and jitrer in the formative time of the streamer, but the trigger gap must be designed so that it does not break down at least until the streamer is well on its way. The deleterious effects of too short a trigger gap or too high a trigger voltage have been reported by several authors. ${ }^{11,13,14,16,19}$ Further, through careful choice of voltage waveform on the trigger pin, it may be possible to encourage the main arc to form directly between main gap electrodes, rather than through the trigger pin tip as an intermediary. Our results also clarify some of the issues involved in operating trigatrons at charging voltages well below $\mathbb{V}_{\mathrm{SB}}$. More work is needed to understand better the streamer formation process and the channel heating processes as they apply to triggered breakdown.

F. E. Peterkin was supported by a National Science Foundation fellowship.

'J. D. Craggs, M. E. Haine, and I. M. Meek, J. Inst. Electr. Eng. 93 A, 963 (1946).

${ }^{2}$ K. J. R. Wikinson, J. Inst. Electr. Eng. 93A, 1090 (1946).

${ }^{3}$ A. S. Husbands and J. H. Higham, J. Sci. Instrum. 28, 242 (1951).

${ }^{4}$ A. M. Sletter and T. J. Lewis, Froc. Inst. Electr. Eng. 104C, 54 (1957).

${ }^{5}$ T. E. Broadbent, Brit. I. Appl. Phys. 8, 37 (1957); T. E. Broadbent and A. H. A. Shlashi, Brit. J. Appl. phys. 14, 687 (1963).

'W. Lampe, Elektrotechnische Z.A 83,591 (1962).

${ }^{7}$ H. Menke and K. H. Schroder, Elcktrotechnische Z.-A 87, 323 (1966).

${ }^{8}$ B. C. Papadias, J. Phys. D 3, 1497 (1970).

${ }^{9} \mathrm{Y}$. Yoshida and K. Sugita, Tech. Reports, Tohoku Univ. 39, 365 (1974); Y. Yoshida, and K. Sugita, J. Phys. Soc. Ipn. 38. 1229 (1975).

${ }^{10}$ Y. Yoshida, J. Phys. Soc. Jpn. 22,1404 (1977).

1'P. I. Shkuropat, Zh. Tekh. Fiz. 39, 954 (1960) (Sov. Phys. Tech. Phys. 5, $895(1961))$

2H. Zwicker and M. Kaufmann, Z. Phys. 180,255 (1964).

13. Y. Shkuropat, Zh. Tekh. Fiz. 39, 1256 (1969) [Sov. Phys. Tech. Phys. 14, $943(1970)]$.

1"T. H. Martin, "Pulse Charged Breakdown," in Digest of Technical Papers, Sth IFEE Pulsed Power Conference, edited by P. J. Turchi and M. F. Rase (IEEE, New York, 1985), pp. 74-83; T. H. Martin (to he published).

15 M. R. Wages, G. Schacter, K. H. Schoenbach, and P. F. Willians, "Streak Photographic Siudies of Trigatron-Triggered Breakdown," in Digest of Technical Popers, 5th IEEE Pulsed Fower Conference, edited by P. J. Turchi and M. F. Rose (IEEE, New York, 1985), pp. 414-417; F. E. Peterkin, P. F. Williams, and G. Schaefer, "Streamer Effocts in High Power Switches," in Digest of Technical Papers, 6th IEEE Pulsed Power Conference, edited by B. H. Bernstein and P. J. Turch (LEEE, New York, 1987), pp. 534-539.

16I. Wells, MSEE thesis, University of New Mexico, December 1987 (unpublished).

${ }_{17}^{17}$. S. Sigmond, J. Appl. Phys 56, 1355 (1984).

${ }^{1 B}$ See, for example, S. K. Dhali and P. F. Willams, Phys. Rev. A 31, 1219 (1985); \$. K. Dhali and P. F. Williams, J. Appl. Phys. 62, 4696 (1987).

${ }^{19}$ A. I. Gerasimov, G. D. Kuheshov, A. E. Pavlovskii, S. Ya. Slyusarenko, and A. S. Fedotkin, Prib. Tekh. Eksp. 18, 111 (1975) Instrum. Exp. Tech. (USSR) 18, $1455\{1975)$. 